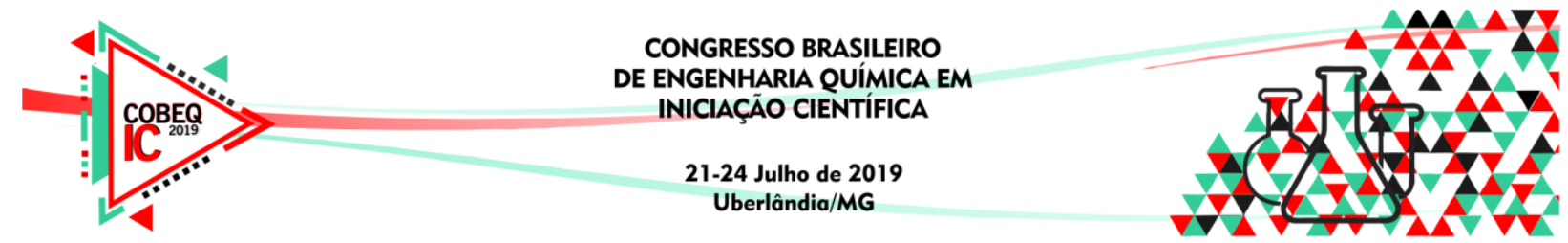

\title{
ESTUDO DO PROCESSO DE SECAGEM DE ARROZ COM CASCA OBTIDO NO MUNICÍPIO LONTRA/MG
}

\author{
J. P. S. FERNANDES ${ }^{1}$, T. A. C. GONÇALVES ${ }^{1}$, V. Q. SILVA ${ }^{1}$, L. F. G., PEREIRA ${ }^{1}$, M. A., \\ B. FREITAS ${ }^{1}$
}

${ }^{1}$ Instituto Federal do Norte de Minas Gerais, Departamento de Engenharia Química

\begin{abstract}
RESUMO - Este trabalho objetivou realizar a comparação do processo de secagem do arroz com casca usando o método convencional em estufa e o intermitente em leito de jorro a fim de sugerir melhorias no processo aos produtores agrícolas locais. Os grãos foram obtidos no município de Lontra/MG e caracterizados fisicamente por meio da porosidade, densidade e esfericidade. O processo de secagem foi realizado com amostras de $200 \mathrm{~g}$ de arroz seco, na umidade de $20 \%$ em base seca à uma temperatura de $30^{\circ} \mathrm{C}$. Para os parâmetros de caracterização do arroz analisados, os resultados mostraram-se coerentes com os apresentados na literatura. Os coeficientes de ajustes polinomiais deram próximos a 1, sendo 0,9789 e 0,9971 na secagem com a estufa e leito de jorro, respectivamente.
\end{abstract}

\section{INTRODUÇÃO}

O Brasil fechou o ano com 10,6 milhões de toneladas de produção de arroz com casca, que apesar de ser quantidade significativa, não superou a de 2015, representando uma queda de 14\% (IBGE, 2016). Por ser o arroz um produto sazonal e de consumo constante, a conservação e armazenagem do produto torna-se indispensável (Ness, 1998). De acordo com Popinigs (1977), geralmente, o teor ideal para se armazenar arroz é definido entre 4 e $8 \%$, o intervalo de 12 a $20 \%$ favorece a proliferação de fungos, de 20 a $45 \%$ aumentam a respiração da semente e de microrganismos, e de 45 a $60 \%$ a semente tende a germinar.

A secagem é um processo de remoção de água, ou outro solvente, de um sólido ou semi-sólido, para uma fase gasosa não saturada (Arrotéia et al., 2017). Nessa operação unitária, é importante considerar que o intervalo da temperatura deve estar entre $25^{\circ} \mathrm{C} \mathrm{e} 65^{\circ} \mathrm{C}$, isso porquê, tanto a forma da semente quanto as propriedades genéticas podem sofrer modificações se nas condições operacionais a temperatura for superior à faixa citada (Valente, 2012). Com o intuito de colaborar com agricultores locais na adaptação de métodos difundidos de secagem às características dos grãos produzidos, o presente trabalho propôs analisar o processo de diminuição da umidade presente no arroz com casca, obtido em LontraMG, usando uma temperatura de operação de $30^{\circ} \mathrm{C}$ pelos métodos convencional e o intermitente com leito de jorro.

\section{MATERIAIS E MÉTODOS}

\subsection{Caracterização e umidificação do arroz}




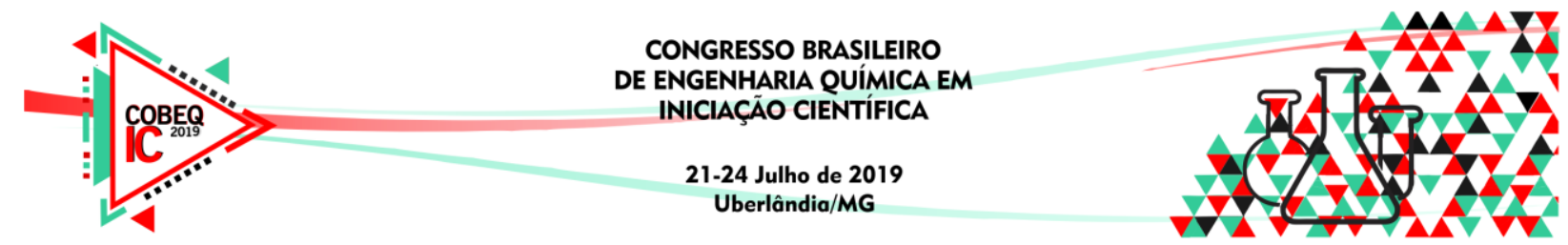

A caracterização do arroz foi feita por meio da porosidade, densidade, e esfericidade dos grãos. Para a caracterização realizou-se a medida das três dimensões do grão (comprimento, largura e espessura) através de paquímetro digital Marbeg (precisão de $0,1 \mathrm{~mm}$ ). No cálculo da área superficial e do volume do grão, aproximou-se a geometria a de um elipsoide.

Verificou-se o volume aparente ocupado dos grãos, adicionando-se uma quantidade conhecida em uma proveta (precisão de $0,1 \mathrm{~mL}$ ) previamente calibrada (conforme a NBR ISSO/IEC 17025). Em seguida, acrescentou-se uma quantidade pré-definida de água a fim de se determinar o volume real. A porosidade foi calculada realizando-se a razão entre o volume dos vazios (diferença entre o volume aparente e o volume real de arroz com casca) e o volume aparente.

Para a umidificação almejou-se teor de umidade encontrado na etapa da colheita, de 18 a $23 \%$, sendo fixado o valor inicial de $20 \%$ de umidade em base seca. Para tal pesou-se, em balança analítica (modelo Shimadzu BL3200H) amostra contendo 200g de arroz com casca e adicionou-se 40 gramas de água, com no mínimo 24 horas de antecedência para a execução dos ensaios de secagem, tanto no leito de jorro quanto na estufa (modelo Equilam YLD2000). Para que o arroz não apresentasse umidade prévia realizou-se a secagem do mesmo em estufa a $60^{\circ} \mathrm{C}$ até que o peso mantivesse constante conforme as aferições de $2 \mathrm{em} 2$ horas.

\subsection{Determinação da velocidade mínima de Jorro}

A determinação do parâmetro fluidodinâmico, velocidade mínima de jorro, foi realizada variando-se a vazão de ar no leito, até que este se expandisse. Foram obtidos os dados de cada par de velocidade do ar/queda de pressão do equipamento, com as sementes à temperatura ambiente. Através do método visual, foi determinada a velocidade mínima de jorro (MATHUR \& EPSTEIN, 1974). A velocidade era regulada no próprio painel de controle do módulo.

\subsection{Processo de secagem}

Os ensaios no leito de jorro, foram realizados na unidade experimental do Laboratório de Engenharia Química do Instituto Federal do Norte de Minas Gerais - Campus Montes Claros (IFNMG). A Figura 1 representa o fluxograma.

Figura 1 - Componentes do sistema (UpControl, 2017)

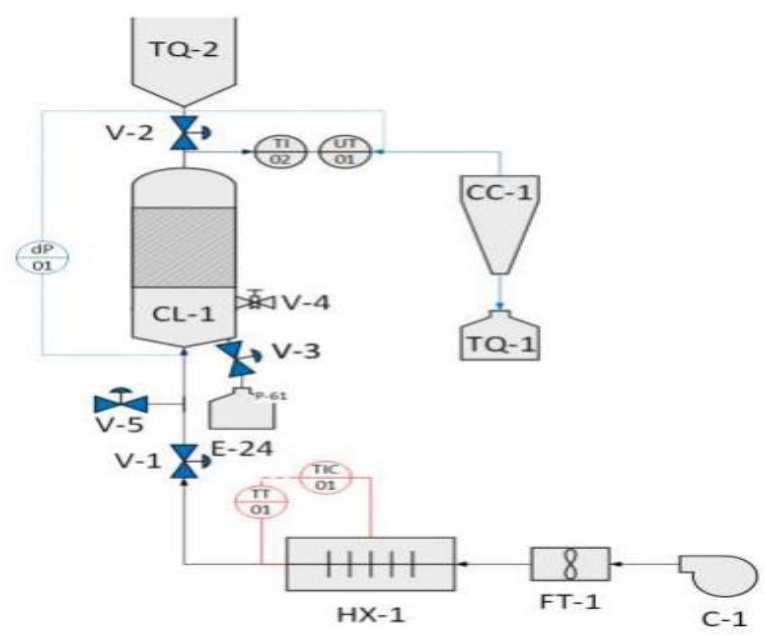




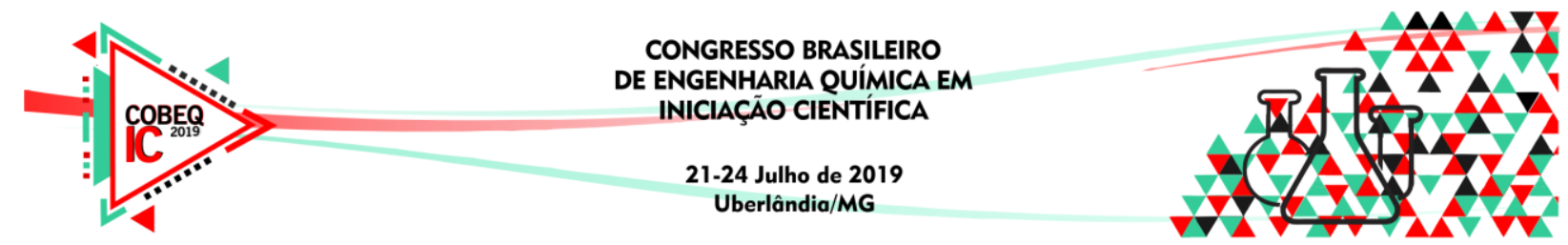

Primeiramente, acionou a chave geral do equipamento, o leito de jorro foi preenchido com uma massa umidificada equivalente a $200 \mathrm{~g}$ de sólido seco, sempre na mesma umidade de início, 20\% em base seca. Alimentou-se o leito já com a vazão de ar previamente estabilizada. Nos intervalos de tempo estabelecidos, anotou-se a queda de pressão, vazão do ar e umidade de saída para posterior comparação. Para a secagem na estufa, amostras de $200 \mathrm{~g}$ de arroz seco, na umidade de $20 \%$ em base seca, foram levados à estufa à uma temperatura de $30{ }^{\circ} \mathrm{C}$, previamente em estado estacionário. Anotou-se a massa do sólido em intervalos de tempo estabelecidos.

\section{RESULTADOS}

\subsection{Propriedades das sementes}

As propriedades físicas das partículas possibilitam prever por meio de cálculos e simulações o processo de secagem e minimizar as quebras dos grãos. Os valores obtidos para os parâmetros abordados encontram-se na Tabela 1 comparados com valores da literatura para o arroz com casca.

Tabela 1 - Propriedades obtidas das amostras de arroz com casca e comparação com literatura

\begin{tabular}{|c|c|c|c|c|c|c|c|}
\hline & \multicolumn{3}{|c|}{ Eixos (mm) } & \multirow{2}{*}{$\begin{array}{c}\rho_{\text {aparente }} \\
(g / m L)\end{array}$} & \multirow{2}{*}{$\begin{array}{c}\rho_{\text {real }} \\
(g / m L)\end{array}$} & \multirow{2}{*}{$\varepsilon$} & \multirow{2}{*}{$\phi$} \\
\hline & Comp. & Larg. & Esp. & & & & \\
\hline Neste trabalho & 8,936 & 2,469 & 1,9593 & 0,5687 & 1,0699 & 0,4684 & 0,390 \\
\hline Ustra et al., 2005 & 9,81 & 2,38 & 1,97 & 0,5338 & 1,1250 & 0,5255 & 0,370 \\
\hline E Souza, 2013 & 9.741 & 2.40 & 2.023 & 0,5626 & 1,2360 & 0,5227 & 0,355 \\
\hline
\end{tabular}

Como pode-se observar as dimensões obtidas neste trabalho encontram-se em conformidade com aquelas registradas na literatura para grãos longos de arroz com casca. A literatura registra faixas de 5 a $10 \mathrm{~mm}$ para o comprimento, 2 a $3 \mathrm{~mm}$ para a largura e 1 a 3 mm para a espessura. A pequena discrepância observada deve-se as diferentes classes de arroz utilizadas pelos autores.

\subsection{Determinação da velocidade mínima de Jorro}

Dentre os parâmetros fluidodinâmicos o mais relevante é a velocidade mínima de jorro. Para o leito de jorro a velocidade mínima encontrada foi de $6,59 \mathrm{~m} / \mathrm{s}$, sendo esse valor calculado para o arroz umidificado. Em condições semelhantes de umidade inicial Ustra et al. (2003) registraram valores de velocidades mínimas entre 1,0 e $1,52 \mathrm{~m} / \mathrm{s}$ para um leito fluidizado contendo arroz com casca. $\mathrm{O}$ valor encontrado por eles é menor que o do leito de jorro, o que era de se esperar, tendo vista que o leito de jorro possui uma maior coluna de sólidos na entrada do fluido (devido ao seu formato cônico na base) o que não ocorre no leio fluidizado (MATHUR \& EPSTEIN, 1974). 


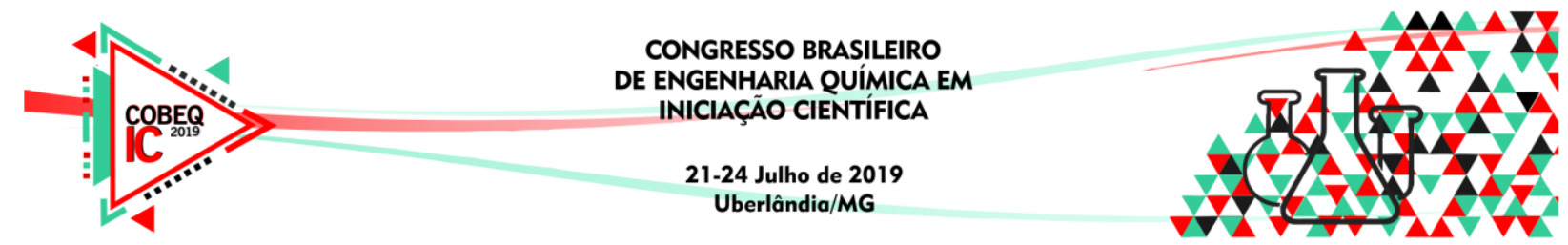

\subsection{Processo de secagem}

A Figura 2a apresenta o comportamento da umidade do grão de arroz com casca a $30^{\circ} \mathrm{C}$ para o processo de secagem em estufa, o valor da umidade mínima atingida foi de 0,1875 ( $\mathrm{g}$ de $\mathrm{H}_{2} \mathrm{O} / \mathrm{g}$ de sólido seco), não alcançando a estabilidade. Na Figura $2 \mathrm{~b}$ encontra-se a curva de secagem para o arroz com casca em leito de jorro a $30^{\circ} \mathrm{C}$.

A curva de secagem encontra-se com comportamento semelhante ao apresentado na literatura. $\mathrm{O}$ valor mínimo alcançado de umidade para a secagem do arroz com casca em leito de jorro após 30 minutos foi de 0,023 ( $\mathrm{g}$ de $\mathrm{H}_{2} \mathrm{O} / \mathrm{g}$ de sólido seco). Fica evidente que para $\mathrm{o}$ mesmo intervalo de tempo a secagem em leito de jorro atingiu uma maior remoção de água presente no grão que em estufa, isso ocorre devido ao jorro proporcionar maior contato entre fluido e sólido pelo movimento cíclico dos grãos, garantindo maiores taxas de transferência de calor e massa.

Figura 2 - Curvas de secagem do arroz com casca a $30^{\circ} \mathrm{C}$ na (a) estufa e no (b) leito de jorro

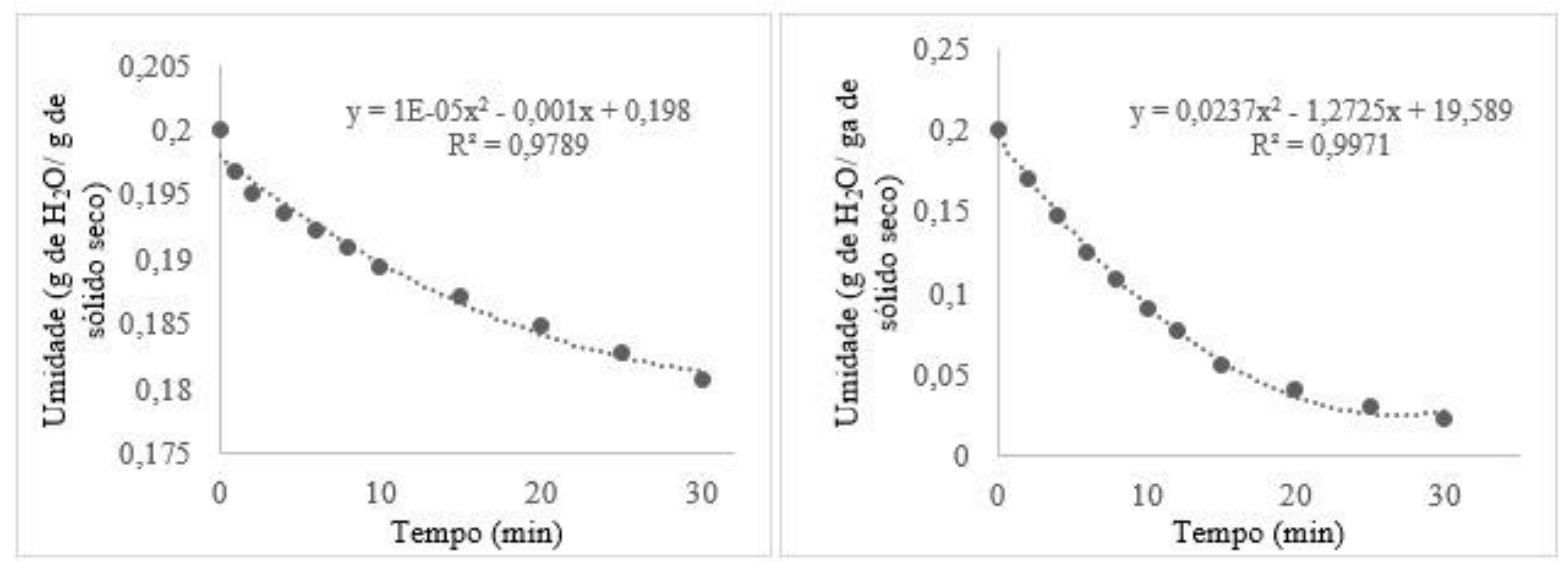

\section{CONCLUSÃO}

A caracterização do arroz com casca obtido no município de Lontra-MG apresentou resultados coerentes com os apresentados na literatura para os parâmetros analisados, demonstrando a eficácia de métodos convencionais ao tipo do arroz. A secagem foi realizada com êxito, mostrando uma diminuição no teor de umidade com o tempo. Dentre os tipos de secagem utilizados o que apresentou uma maior remoção de umidade do sólido, em um mesmo intervalo de tempo, foi o leito de jorro atingindo uma umidade mínima de 0,023 (g de $\mathrm{H}_{2} \mathrm{O} / \mathrm{g}$ de sólido seco) após 30 minutos. Com isso, verifica-se que os agricultores locais podem empregar tanto o leito de jorro quanto o método em estufa para a diminuição do teor de umidade. Em trabalhos futuros almeja-se estudar melhores condições do processo através da variação da temperatura em ambos os métodos.

\section{NOMENCLATURA}

CL-1 - Coluna do leito de jorro;

TI-0 - Quadro de comando para controle do ar; 


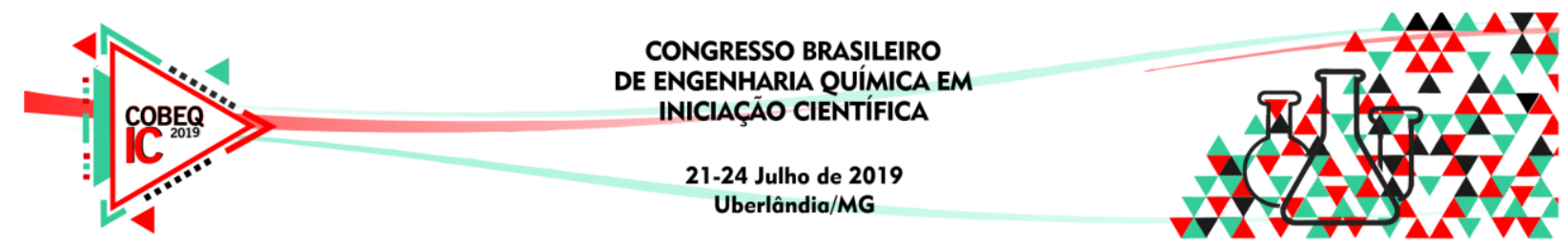

C-1 - Chave liga/desliga para o compressor;

FT-1 - Anemômetro (modelo HIGHMED HM-385);

V-5 - Válvula de medição;

V-i - Válvulas do processo, onde i é a numeração da válvula;

E-4 - Recipiente de recolhimento;

TQ-2 - Silo de alimentação;

UT-1 - Termohigrômetro (modelo AKSO AK625);

PI-1 - Manômetro;

CC-1 - Ciclone;

TQ-1 - Coletor do ciclone;

HX-1 - Pré-aquecedor;

o - Densidade;

$\boldsymbol{\varepsilon}$ - Porosidade;

$\phi-$ Esfericidade.

\section{REFERÊNCIAS}

ARROTÉIA, D. R. Estudo do processo de secagem da linhaça em leito fluidizado e em leito de jorro. The Journal of Engineering and Exact Sciences - JCEC, vol. 03, n. 02(2017) 215-224.

E SOUZA, Á. B. M. Physical, thermal and aerodynamic properties of rice grain varieties BR IRGA 409 and BRS Primavera. Current Agricultural Science and Technology, v. 19, n. $1,2013$.

INSTITUTO BRASILEIRO DE GEOGRAFIA E ESTATÍSTICA. Levantamento Sistemático de Produtos Agrícolas. Disponível em: <ftp://ftp.ibge.gov.br/Producao_Agricola/ Levantamento_Sistematico_da_Producao_Agricola_[mensal]/Fasciculo/2016/lspa_201 612_20170222_133000.pdf>. Acesso em: 05 de Março de 2018.

MATHUR, K.B.; EPSTEIN, K.A. Spouted Beds. New York: Academic Press, 1974.

NESS, A. R. R. Qualidade do arroz em casca, seco e armazenado em silos metálicos com aeração controlada, 1998, 108 p. Dissertação (Mestrado em Engenharia de Alimentos) - Fundação Universidade Federal do Rio Grande - Rio Grande.

POPINIGIS, F. Fisiologia da Semente. Brasília, AGIPLAN, 1985. 289p.

UPCONTROL. Módulo de secagem em leito de jorro e leito fixo. Manual de instruções. p. 78. Porto Alegre, 2017. 


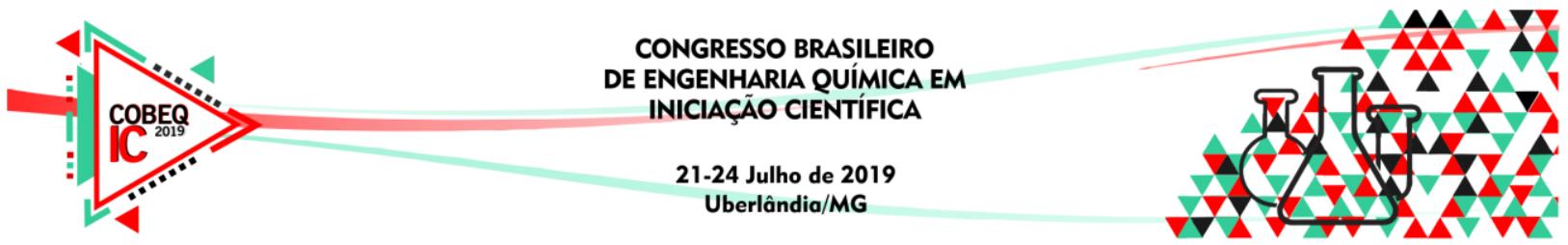

USTRA, L. A. R. Secagem de grãos de arroz em leito fluidizado. Dissertação (Mestrado) Programa de Pós-Graduação em Ciência e Tecnologia Agroindustrial. Faculdade de Agronomia Eliseu Maciel. Universidade Federal de Pelotas. Pelotas, 2005.

Valente, M. C. C.; Costa, C. M. L.; Souza, C. A. G. Cinética de secagem em leito fluidizado de sementes de linhaças (Linumusitatissimum L.). Rev. de Ciências. Exatas, v. 27/31, n. 2, p. 110-120, jul.-dez. 2012. 